\title{
Controlling substrate specificity and product regio- and stereo-selectivities of P450 enzymes without mutagenesis
}

\author{
Vanja Polic, Karine Auclair* \\ Department of Chemistry, McGill University, 801 Sherbrooke Street West, Montreal, Quebec H3A 0B8, Canada
}

\section{A R T I C L E I N F O}

\section{Article history:}

Received 19 April 2014

Revised 12 June 2014

Accepted 17 June 2014

Available online 25 June 2014

\section{Keywords:}

Anchoring molecule

Biocatalysis

Chemical auxiliary

Decoy molecule

Directing group

Fatty acid

Molecularly imprinted polymer

Perfluorinated carboxylic acid

\begin{abstract}
A B S T R A C T
P450 enzymes (P450s) are well known for their ability to oxidize unactivated C-H bonds with high regioand stereoselectivity. Hence, there is emerging interest in exploiting P450s as potential biocatalysts. Although bacterial P450s typically show higher activity than their mammalian counterparts, they tend to be more substrate selective. Most drug-metabolizing P450s on the other hand, display remarkable substrate promiscuity, yet product prediction remains challenging. Protein engineering is one established strategy to overcome these issues. A less explored, yet promising alternative involves substrate engineering. This review discusses the use of small molecules for controlling the substrate specificity and product selectivity of P450s. The focus is on two approaches, one taking advantage of non-covalent decoy molecules, and the other involving covalent substrate modifications.
\end{abstract}

(c) 2014 Elsevier Ltd. All rights reserved.

\section{Introduction}

P450 enzymes (P450s), are heme-dependent monooxygenases involved in processes such as biosynthesis of steroids and natural products, as well as xenobiotic metabolism. ${ }^{1,2}$ Of particular interest is their remarkable ability to hydroxylate unactivated $\mathrm{C}-\mathrm{H}$ bonds with good-to-excellent regio- and stereoselectivity. ${ }^{1-4}$ Success has been achieved in the engineering of P450s for expansion of substrate scope, alteration of regioselectivity or for production of small molecules, drugs or drug metabolites. ${ }^{5-8}$ The large majority of mechanistic and engineering studies have focused on bacterial P450s due to their soluble nature and higher activity in vitro. ${ }^{1,9}$ Using mutagenesis, directed and random evolutions, $\mathrm{P} 450_{\mathrm{BM}}$ for instance has been extensively engineered to oxidize unnatural substrates such as alkanes, ${ }^{10,11}$ indole to indigo and indirubin, ${ }^{12}$ terpenes, ${ }^{13}$ steroids and alkaloids. ${ }^{14}$ More recently, incorporation of unnatural amino acids into $\mathrm{P} 450_{\mathrm{BM}}$ also allowed for enhancement of activity and alteration of regioselectivity. ${ }^{15}$ Effort has also been invested into using computational modelling ${ }^{16,17}$ and fingerprinting $^{17-19}$ of P450s to guide rational engineering of the enzymes to obtain novel regio- and stereoselectivities. Mammalian P450s, on the other hand, have generated great interest mostly because of

\footnotetext{
* Corresponding author. Tel.: +1 514398 2822; fax: +1 5143983797.

E-mail address: karine.auclair@mcgill.ca (K. Auclair).
}

their important role in drug metabolism. The pharmaceutical industry has contributed to reveal the exceptional ability of some human P450s to oxidize a large variety of substrates while distinguishing between multiple sterically and electronically similar $\mathrm{C}-\mathrm{H}$ bonds, yet without generating over-oxidation products. ${ }^{2,3,20,21}$ Whereas the high substrate promiscuity of P450s can be an attractive quality for a biocatalyst, our current inability to predict the site(s) of oxidation creates a paradox. Here we review some strategies aiming to manipulate substrate specificity and predict products of P450 transformations without the use of mutagenesis. These approaches use small molecules to affect substrate binding either via non-covalent or covalent interactions.

\section{Non-covalent interactions between P450s and small molecules as a way to modify substrate specificity and regioselectivity}

This section describes research where inert dummy molecules, also referred to as decoys, are used to control the site of P450 oxidation by blocking a part of the active site and thus constraining the substrate into a specific binding orientation. ${ }^{22}$ The decoys are often structurally similar to the natural substrate but are not turned over by the enzyme. ${ }^{22}$ Two types of decoy molecules have been explored for their P450-directing capabilities: (1) short-chain fatty acids, and (2) perfluorinated fatty acids. 
a) Myristic acid oxidation

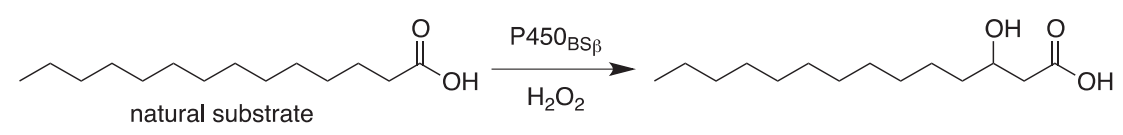

b) Guaiacol oxidation

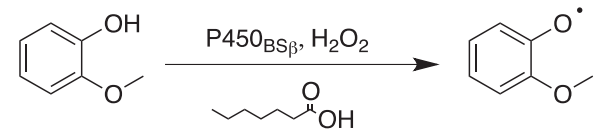

c) Styrene oxidation

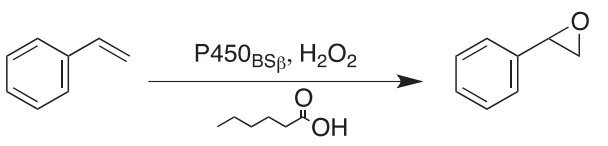

d) Ethylbenzene oxidation

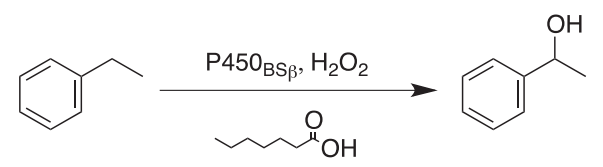

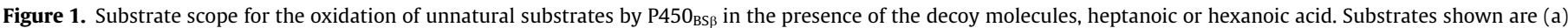
myristic acid, (b) guaiacol, (c) styrene, and (d) ethylbenzene, along with the major product of their oxidation by $\mathrm{P} 450_{\mathrm{BS} \beta} \cdot{ }^{22}$

\subsection{Effect of short-chain fatty acid decoy molecules on $\mathrm{P}^{450_{\mathrm{BS} \beta}}$ catalysis}

$\mathrm{P}_{450} \mathrm{BS \beta}_{\beta}$ is a soluble and self-sufficient P450 enzyme isolated from Bacillus subtilis. It typically catalyzes the $\alpha$ - and $\beta$-hydroxylation of long-chain fatty acid substrates, such as myristic acid, with good regioselectivity. ${ }^{23}$ In 2007, Watanabe and co-workers took advantage of short-chain fatty acids to expand the substrate scope of $\mathrm{P} 450_{\mathrm{BS} \beta}$ and enable the transformation of the unnatural substrates guaiacol, styrene, ethylbenzene and thioanisole (Fig. 1). ${ }^{22,24}$ The applied short-chain fatty acids were found to act as ligands of $\mathrm{P} 450_{\mathrm{BS} \beta}$, mimicking part of the substrate and leaving a small portion of the substrate binding pocket available near the heme iron for the unnatural substrate to occupy. Guaiacol oxidation by $\mathrm{P} 4 \mathrm{BO}_{\mathrm{BS} \beta}$ was optimized with the addition of carboxylic acid decoy molecules varying in length from 2 to 10 carbons. $^{22}$ Although many of the acids promoted guaiacol oxidation, heptanoic acid was the most successful with a turnover rate 10 -fold higher than that of myristic acid hydroxylation. The rate enhancement was attributed to the decoy molecule keeping the catalytic cycle 'on', which long-chain fatty acid substrates normally turn on when they bind and 'off' when the product dissociates. ${ }^{22}$ As expected, in the presence of myristic acid, no oxidation of guaiacol occurred. Activation of $\mathrm{P}^{4} 50_{\mathrm{BS} \beta}$ by carboxylic acid decoy molecules was also observed for styrene epoxidation and ethylbenzene hydroxylation. ${ }^{22}$ Styrene epoxidation proceeded with both regioselectivity and enantioselectivity greater than $80 \%$, while ethylbenzene hydroxylation reached $68 \%$ ee $(R)$ at best. Altogether, these results demonstrate that $\mathrm{P} 4 \mathrm{BO}_{\mathrm{BS} \beta}$ can catalyze the oxidation of non-fatty acid substrates when tricked into misrecognizing shortchain fatty acids instead of the natural long chain fatty acids. Crystal structure analysis suggested that fatty acids shorter than 10 carbon long might be too short to extend into the hydrophobic substrate access channel, resulting in loose fixation of the hydrophobic tail. ${ }^{25}$ This may prevent hydroxylation of the decoy molecules while allowing entry of the small molecule. ${ }^{20}$

To investigate the effect of variations in the structure of the decoy molecule on the stereochemical outcome of the reaction, Watanabe and colleagues examined sulfoxidation of thioanisole (Table 1$) \cdot{ }^{24}$ Most of the decoy molecules examined favored the product with the $R$ configuration at the sulfur with modest ee. In fact the turnover was correlated $(R=0.8187)$ with the \% ee for the product with $R$ configuration. Branched carboxylic acids with and without a chiral center were also tested with the aim of obtaining the $S$-isomer but did not induce the desired stereochemical inversion. It was noted that over-oxidation to the sulfone product was not observed.

Interestingly, addition of $p$-methylphenylacetic acid ( $p$-MPAA) or $p$-isopropylphenylacetic acid to the enzymatic reaction mixture was successful to favor the $S$ enantiomeric product. ${ }^{24}$ Molecular modeling simulations with phenylacetic acid (PAA) and $p$-MPAA showed that for $p$-MPAA, the methyl group is positioned over the porphyrin ring creating steric bulk near thioanisole, which may favor positioning of the pro-S lone pair closer to the heme (Fig. 2). This is an interesting example of a non-mutagenic method to reverse the stereoselectivity of a P450-catalyzed reaction.

\subsection{Effect of perfluorinated fatty acid decoy molecules on $\mathbf{P 4 5 0}_{\text {ВMз }}$ catalysis}

Over two decades ago, Baker and co-workers reported that the activity of microsomal P450s could be enhanced with the addition of fluoroethane derivatives (fluorinated, chlorinated and/or brominated). ${ }^{26-29}$ More recently, perfluorinated fatty acids have proven to be useful decoy molecules to divert $\mathrm{P} 4 \mathrm{O}_{\mathrm{BM}}$ into accepting nonnatural substrates, especially small alkanes. ${ }^{30,31} \mathrm{P} 450_{\mathrm{BM} 3}$ is another self-sufficient enzyme encoded by Bacillus megaterium. It catalyzes the hydroxylation of long-chain fatty acids, such as myristic and palmitic acid, at the $\omega-1, \omega-2$, and/or $\omega-3$ positions. Although $\mathrm{P}_{450_{\mathrm{BM}}}$ has a large active site which can accommodate multiple substrates at once, molecules that are not fatty acids are typically not transformed by the enzyme. ${ }^{32,33}$ The carboxylate group in particular is required for catalytic activity. ${ }^{32,33}$ The large size of the active site poses an additional challenge for biocatalytic applications; several binding orientations are accessible, potentially leading to multiple products. $^{30}$ Two studies reported by Reetz ${ }^{30}$ and Watanabe ${ }^{32}$ independently demonstrated that perfluorocarboxylic acids (PFCs) can be used as decoy molecules to favor the transformation of unnatural substrates by $\mathrm{P} 40_{\mathrm{BM}}$ without resorting to mutagenesis. In the context of oxidations, PFCs are an inert alternative to fatty acids due to 
Table 1

Sulfoxidation of thioanisole catalyzed by $\mathrm{P}^{4} 50_{\mathrm{BS} \beta}$ in the presence of carboxylic acid decoy molecules ${ }^{24}$

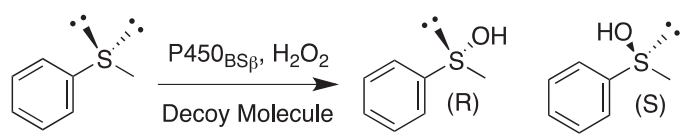

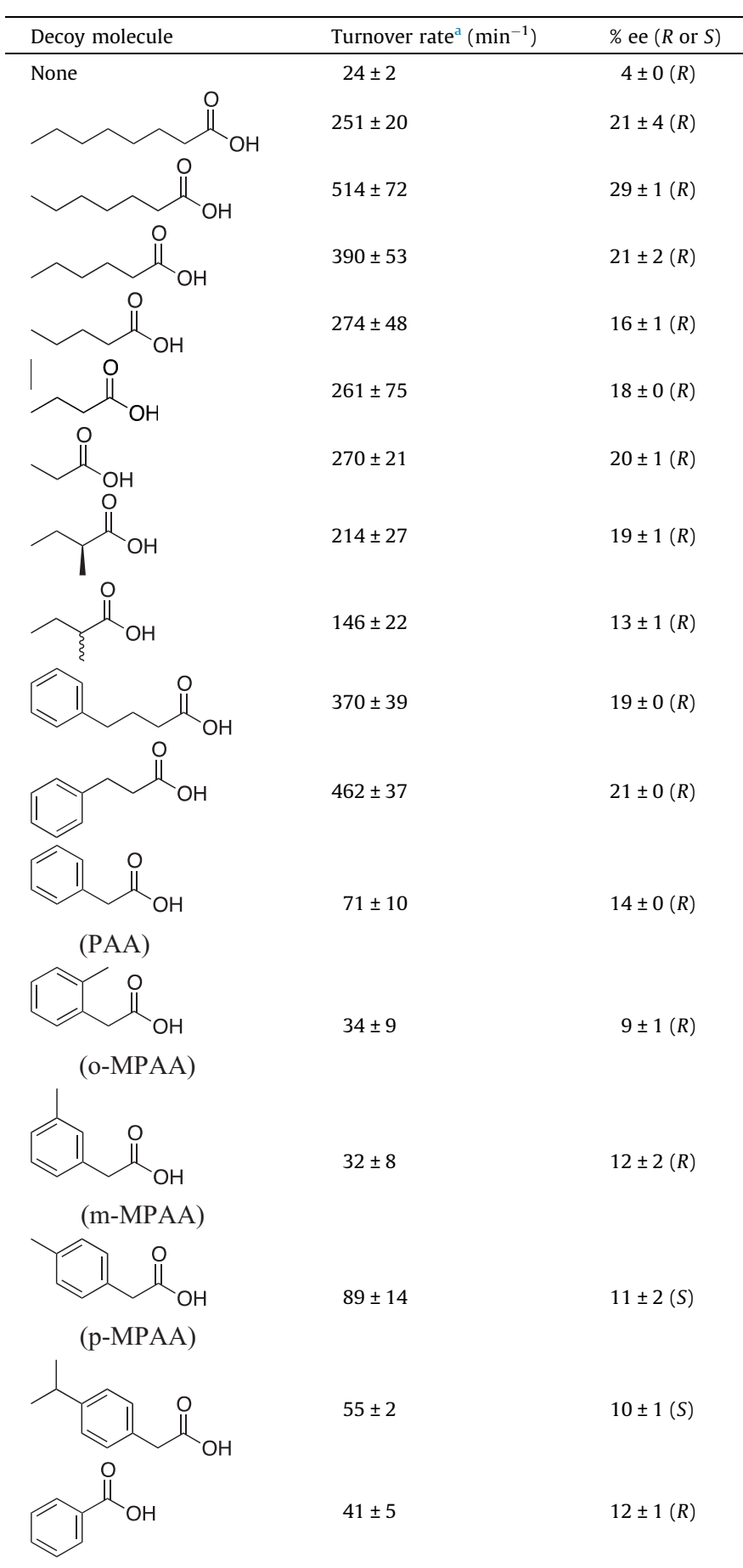

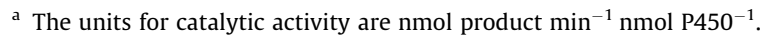

the greater bond-dissociation energy of $\mathrm{C}-\mathrm{F}$ bonds $\left(116 \mathrm{kcal} \mathrm{mol}^{-1}\right)$ compared to that of $\mathrm{C}-\mathrm{H}$ bonds $\left(95-99 \mathrm{kcal} \mathrm{mol}^{-1}\right){ }^{31}$ Although PFCs and fatty acids have similar hydrophobicity, PFCs are considerably larger than fatty acids. ${ }^{34}$

Using PFCs with 7-14 carbon lengths, Reetz and Watanabe independently confirmed that PFCs bind $\mathrm{P} 450_{\mathrm{BM} 3}$ and create (a)

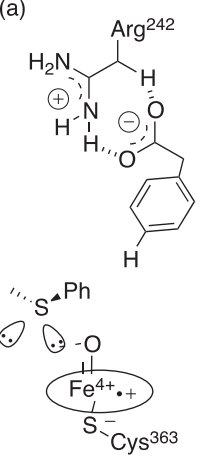

(R)-selectivity (b)

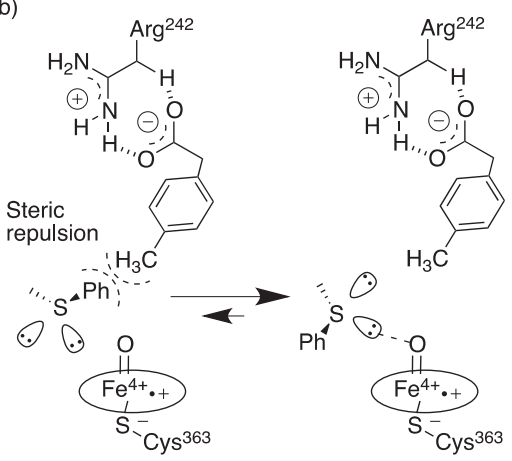

(S)-selectivity
Figure 2. Suggested transition states for stereochemical inversion during the sulfoxidation of thioanisole by $\mathrm{P} 450_{\mathrm{BS} \beta}$ with (a) PAA and (b) $p$-MPAA as illustrated by Fujishiro et al. ${ }^{24}$

Table 2

Conversion rates of gaseous molecules by $\mathrm{P}^{4} 50_{\mathrm{BM}}$ in the presence of PFCs

\begin{tabular}{|c|c|c|c|c|}
\hline Substrate & $\mathrm{PFC}^{\mathrm{a}}$ & $\begin{array}{l}\text { Rate }^{\mathrm{b}} \\
\left(\mathrm{min}^{-1}\right)\end{array}$ & Regioselectivity & Refs \\
\hline & C11 & 1021 & & 30 \\
\hline & C10 & 67 & & 31 \\
\hline & $\mathrm{C7}$ & 3632 & & 30 \\
\hline & $\mathrm{C} 10$ & 113 & & 31 \\
\hline & $\mathrm{C} 11$ & 525 & 2-/3-Hexanol = 77:23 & 30 \\
\hline & C9 & 1184 & $\begin{array}{l}2-/ 3-/ 4- \\
\text { Octanol = 10:42:48 }\end{array}$ & 30 \\
\hline & C9 & 110 & & 31 \\
\hline & $\mathrm{C9}$ & 476 & 2-/3-Hydroxy = 88:12 & 30 \\
\hline & C9 & 891 & Only 2-hydroxy & 30 \\
\hline & C11 & 3241 & Only 2-hydroxy & 30 \\
\hline
\end{tabular}

a Optimal perfluorinated carboxylic acid reported.
b Observed turnover rates.

Table 3

Hydroxylation of aromatic rings by $\mathrm{P}^{4} 50_{\mathrm{BM}}$ in the presence of $\mathrm{PFCs}^{36}$

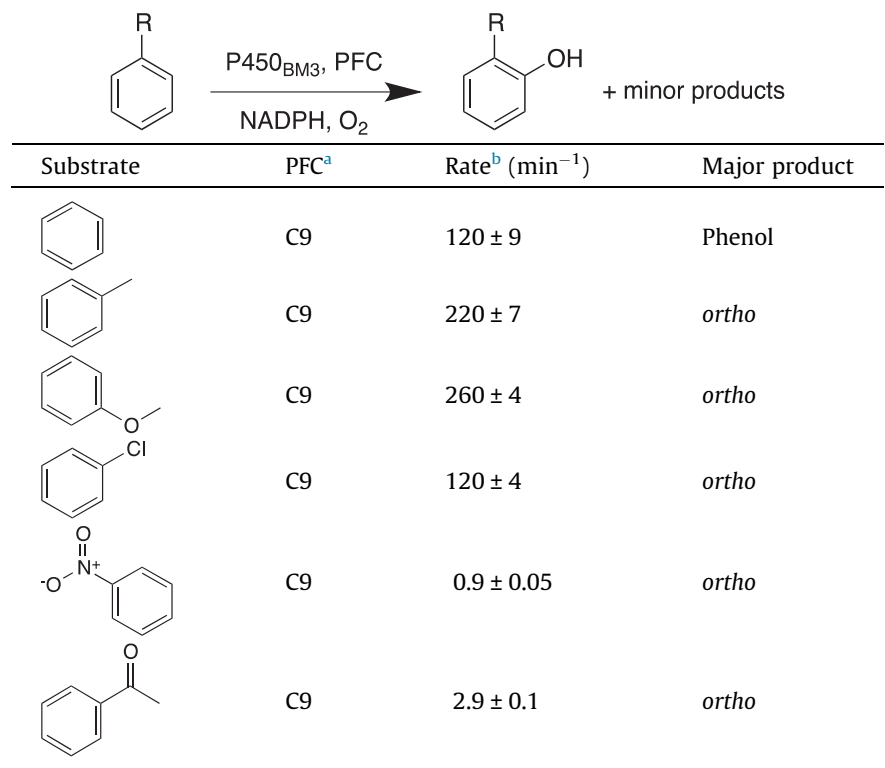

a The chain length of PFC that elicited the greatest effect.

b Rates are given in units of $\mathrm{min}^{-1}$ per P450. Uncertainty is given as the standard deviation from at least three measurements. 


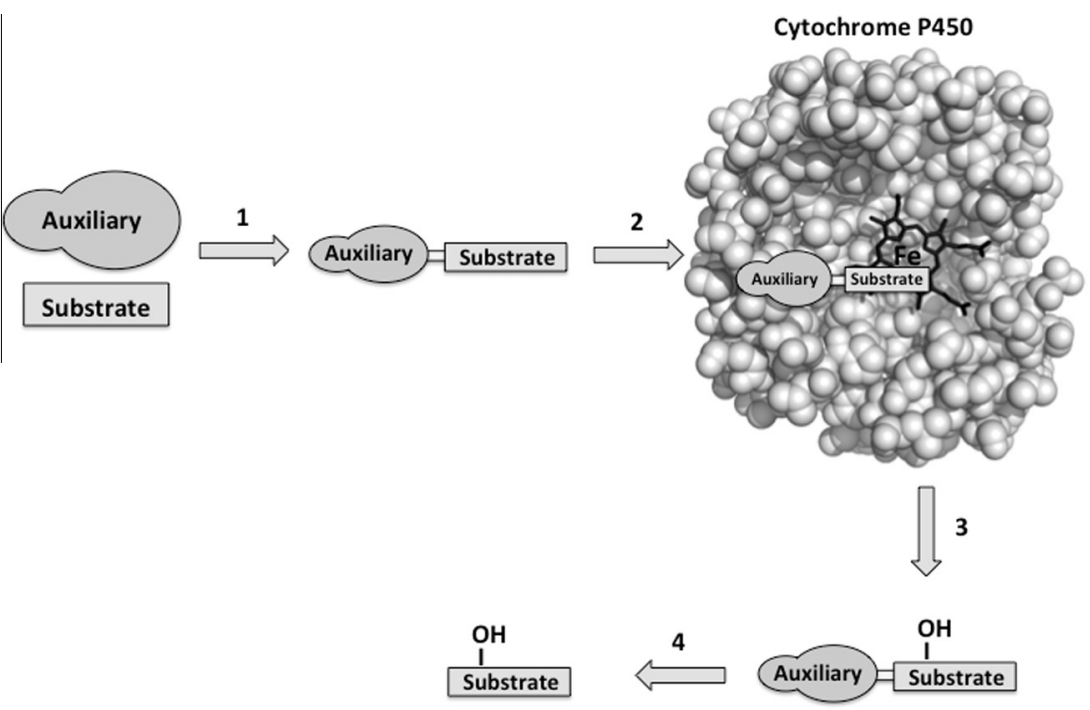

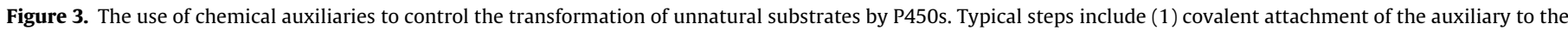
substrate of interest, (2) transformation of the auxiliary-substrate by the enzyme, (3) product release, and (4) chemical cleavage of the auxiliary.

\section{a) Oxidation of cyclopentanoic acid}

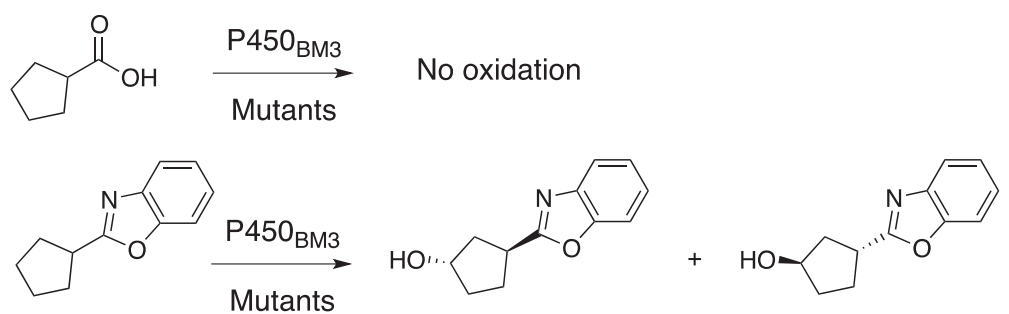

b) Selective deprotection of monosaccharides
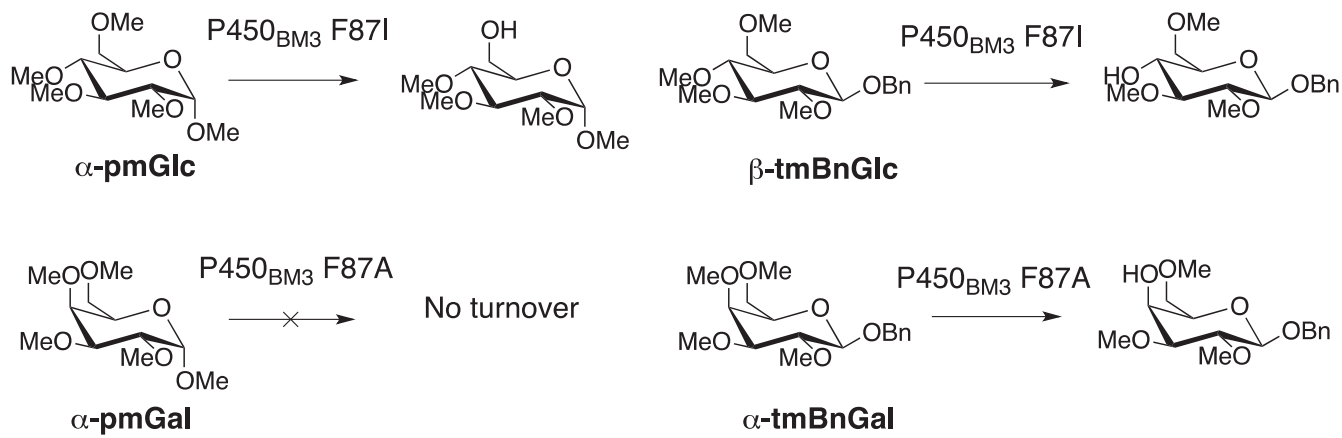

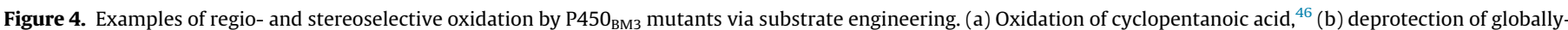
methylated glucose (glc) and galactose (gal). ${ }^{47}$

significant steric bulk in the active site. Moreover, the PFCs activate the enzyme by displacing the distal water molecule and inducing a low-to-high spin state shift of the heme iron. ${ }^{31}$ The PFCs were assessed for their ability to direct the hydroxylation of small substrates ranging from methane to octane, including some constitutional isomers of hexane (Table 2). ${ }^{30,31}$ The results point to longer PFCs as better decoys to favor the desired transformations. In general, PFCs enhanced enzymatic turnover but had little effect on regio- and stereoselectivity. Indeed, multiple products were generated and this was attributed to inconsistent orientation of the alkanes due to the lack of functional groups. ${ }^{30,31}$ While the conversion of propane to propanol in the presence of PFC10 proceeded successfully, ${ }^{30}$ the original conclusion that methane was oxidized to methanol was later refuted. ${ }^{35}$ In the presence of decanoic acid however $\mathrm{P}^{4} 5 \mathrm{~B}_{\mathrm{BM}}$ did not convert propane to propanol, suggesting that the fluorine atoms in the decoy molecule are crucial for coercing the enzyme to accept small alkane substrates. ${ }^{31}$

More recently, Watanabe, Shoji and colleagues reported successful hydroxylation of aromatic rings such as those of benzene, toluene, anisole, chlorobenzene, nitrobenzene and acetophenone 
Table 4

The scope and turnover of desosamine-linked unnatural substrates by $\mathrm{PikC}_{\mathrm{D}^{2} \mathrm{~N}^{-}}$ RhFRED $^{45}$

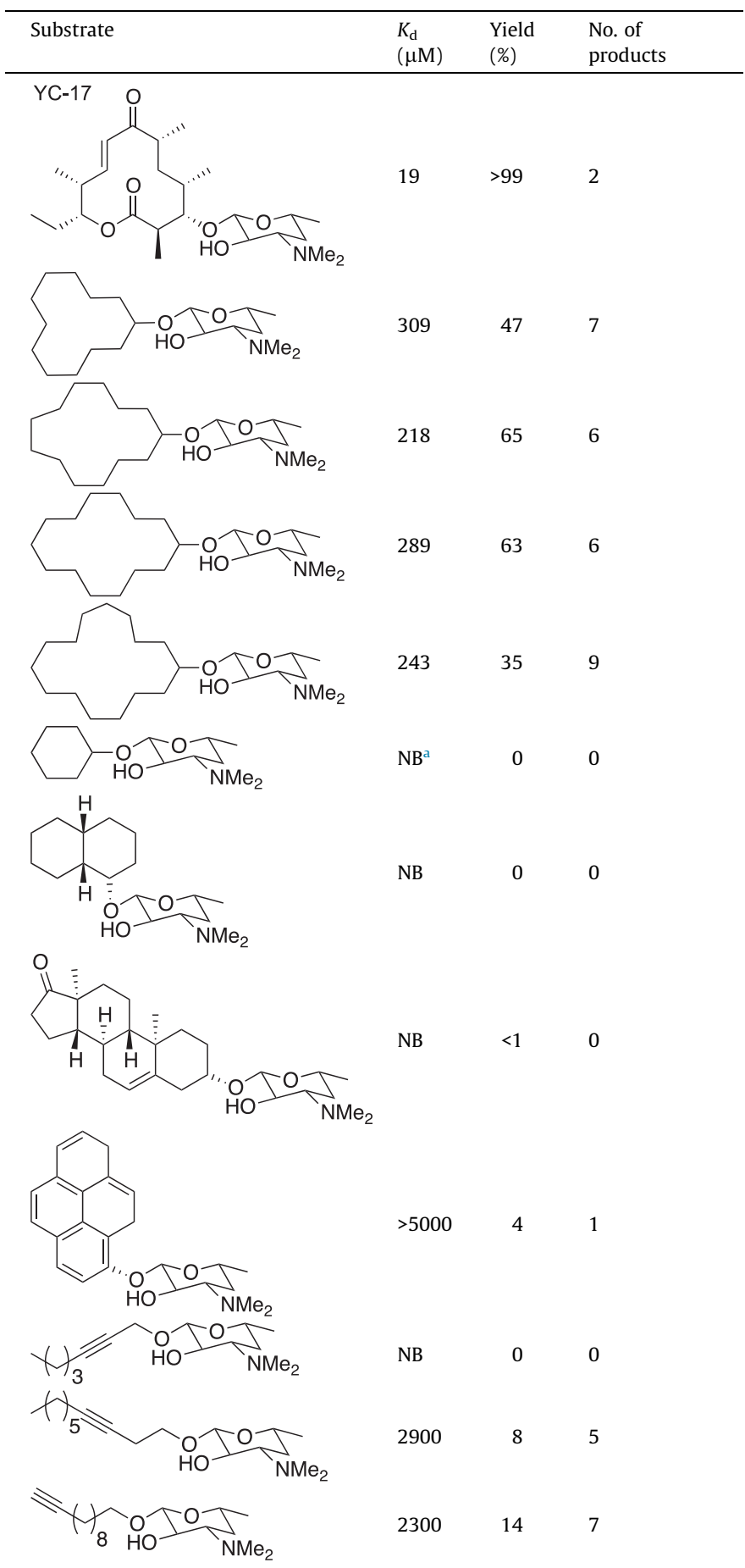

${ }^{\text {a }} \mathrm{NB}$, binding below detection limit.

using $\mathrm{P}_{450} 0_{\mathrm{BM}}$ and various PFCs (Table 3 ). ${ }^{36}$ The transformations proceeded with exclusive formation of phenol derivatives but the turnover rate diminished with the presence of electron-withdrawing groups on the ring. The major hydroxylation site was always ortho to the existing aromatic substituent, even with meta directing groups. Thus it was assumed that the regioselectivity is controlled by the substrate binding pocket. ${ }^{36}$

Overall, decoy molecules provide a simple and quick way for increasing the substrate scope of P450s without the need for protein mutagenesis. The molecules can also be used to influence the regio- and stereoselectivity of P450-catalyzed reactions. This elegant strategy remains to be expanded to P450s other than $\mathrm{P} 450_{\mathrm{BS} \beta}$ and $\mathrm{P} 40_{\mathrm{BM} 3}$, and especially to drug-metabolizing P450s, which often show cooperative behavior resulting from the simultaneous binding of multiple substrates.

\section{Covalent modifications of substrates as a way to control substrate specificity, regioselectivity and stereoselectivity of P450s}

The second non-mutagenic strategy reviewed here applies substrate engineering to control oxidation by P450s. Early studies with monooxygenases suggested that the presence of specific functional groups can improve substrate acceptance by biocatalysts. ${ }^{37-44}$ Substrate engineering may involve the covalent addition of a specific recognition motif, a chemical auxiliary or a directing group, to an unnatural substrate with the aim of facilitating recognition by the enzyme and favoring a specific productive binding orientation (Fig. 3). ${ }^{43,45}$

\subsection{Covalent modifications to impose unnatural substrates to bacterial P450s}

One of the earlier groups to apply substrate engineering with P450s was that of Munzer for the expansion of the substrate scope of $\mathrm{P}_{450}{ }_{\text {вм } 3}{ }^{46}$ Protein mutagenesis was combined with the use of 2-aminophenol as a chemical auxiliary (via formation of a benzoxazole ring, see Fig. 4a) for establishing cyclopentanoic acid as a substrate of numerous $\mathrm{P}^{4} 50_{\mathrm{BM}} 3$ mutants. ${ }^{46}$ The auxiliary not only ensured that cyclopentanoic acid was transformed by the enzyme but also imparted selectivity towards production of two out of four possible diastereoisomers. In a separate study with the same P450, Arnold and co-workers manipulated protecting-group moieties and the stereochemistry at the anomeric carbon of globally-protected monosaccharides to control the regioselectivity of $\mathrm{P}_{450} \mathrm{BM}_{3}$-catalyzed deprotection further away on the sugar (Fig. 4b). ${ }^{47}$ Interestingly inverting the stereochemistry from $\alpha$ to $\beta$ and benzylation of the anomeric position turned otherwise unreactive molecules into substrates that are regioselectively deprotected at $0-4$ by $\mathrm{P}^{4} 50_{\mathrm{BM} 3} \mathrm{~F} 87 \mathrm{~A}$ or F87I mutants. In combination, these studies demonstrate the ability of substrate engineering to expand the substrate scope of $\mathrm{P}^{4} 50_{\mathrm{BM}}$ mutants while imparting some selectivity.

PikC is a P450 enzyme isolated from Streptomyces venezuelae and involved in the hydroxylation of the 12- and 14-membered ring macrolides YC-17 and narbomycin. ${ }^{48,49}$ Inspired by the structures of YC-17 and narbomycin, a desosamine glycoside moiety was designed to favor hydroxylation of carbocyclic rings by PikC. ${ }^{45}$ A self-sufficient PikC fusion mutant, PikC $_{\mathrm{D} 50 \mathrm{~N}}-\mathrm{RhFRED}^{50}$ was evaluated for the oxidation of a series of carbocyclic rings ranging in size from 12 to 15 carbons and linked to a desosamine glycoside, the auxiliary (Table 4). In each case multiple hydroxylation products were detected with the major regioisomer typically displaying the hydroxyl group at the site most distant from the chemical auxiliary. No over-oxidation to ketone products and no hydroxylation of the auxiliary were detected. Molecules other than carbocyclic rings were poor substrates or were not transformed at all by the enzyme. Crystal structure analysis suggested that rigidity of the substrates is a major determinant for the regioselectivity of $\mathrm{PikC}_{\mathrm{D} 50 \mathrm{~N}}$-RhFRED. The desosamine moiety can also adopt two significantly different binding modes, causing flipping of the substrate. This work has recently been extended by the same group to examine other auxiliaries containing the tertiary amine moiety found in desosamine. ${ }^{51}$ The natural substrate YC-17 is hydroxyl- 

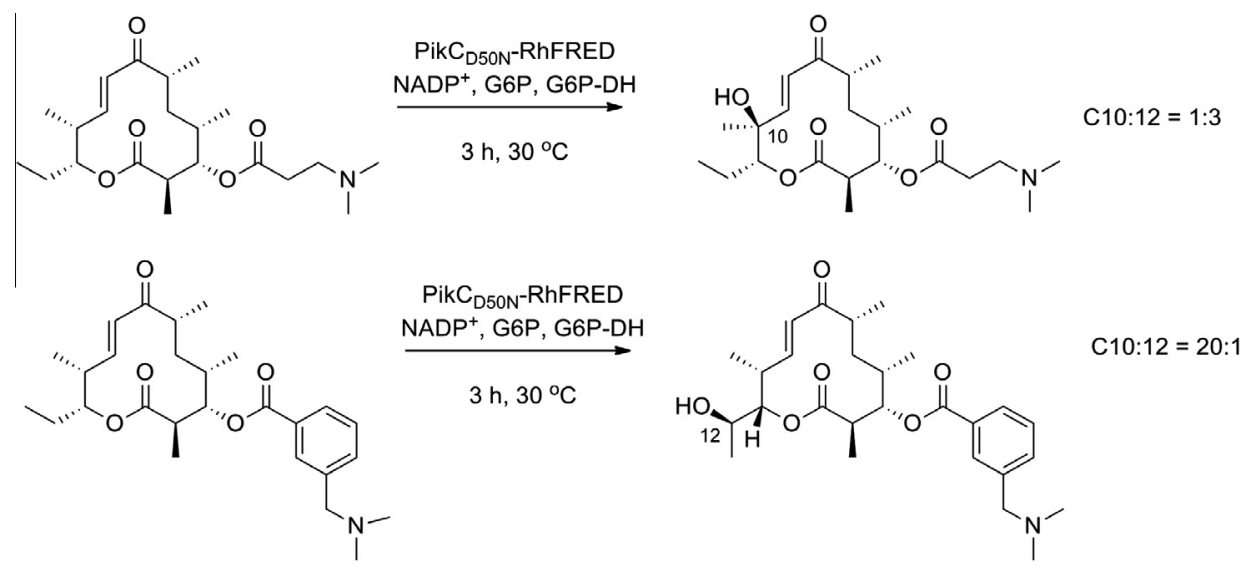

Figure 5. Regioselective oxidation of YC-17 analogues with tertiary amine auxiliaries. ${ }^{51}$

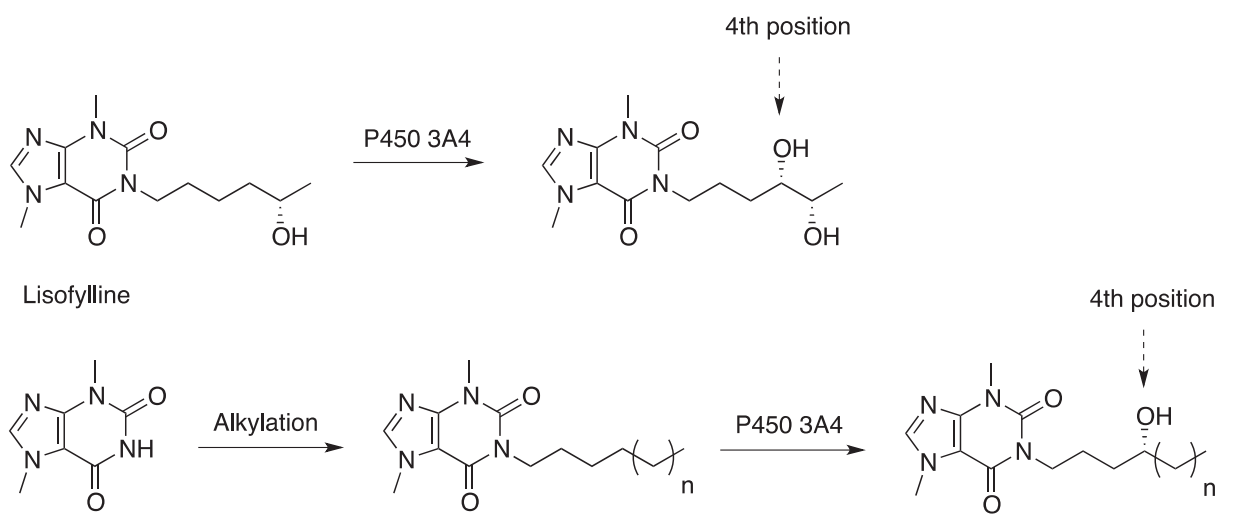

Theobromine

Figure 6. Oxidation of lisofylline and theobromine derivatives by P450 3A4.

ated by PikC at C-10 and C-12 in a $1: 1$ ratio. The regioselectivity of the monohydroxylation of YC-17 analogues by PikC was investigated with various tertiary amines. The authors showed that the regioselectivity of YC-17 hydroxylation depends on the presence, length, rigidity and stereochemistry of the tertiary amine. ${ }^{51}$ By varying the chemical auxiliary from 3-(dimethylamino)propanoic acid to $m$-(dimethylamino)benzoic acid they were able to tune the selectivity of oxidation to favor either C12 ( 3 fold), or C10 (20 fold) (Fig. 5). Interestingly, replacement of the tertiary amine group with an isopropyl group did not yield turnover of the analogues by the enzyme. By removing the majority of the desosamine structure and keeping only the tertiary amine moiety, the authors demonstrated the importance of preserving the active site salt bridge formed between the tertiary amine moiety of an auxiliary and an active site glutamic acid.

\subsection{Covalent modifications to extend the substrate promiscuity and predict the regio- and stereoselectivity of mammalian P450s}

Substrate promiscuity is considered a highly attractive quality in a versatile biocatalyst, and many mammalian P450s are unequalled in this aspect. ${ }^{2,52-54}$ Human P450 3A4 for example accounts for the metabolism of approximately $50 \%$ of all xenobiotics. ${ }^{55}$ Due to its large and flexible active site P450 3A4 is inherently highly promiscuous and unpredictable in terms of substrate specificity and product selectivity. Through substrate engineering the Auclair group has demonstrated that the regio- and stereoselectivity of P450 3A4 and P450 2E1 can be controlled in a predictable manner. ${ }^{56,57}$
The use of theobromine as a chemical auxiliary was reported to not only favor the transformation of unnatural substrates by P450 3A4 but also to allow prediction of the enzyme regio- and stereoselectivity. ${ }^{56}$ The theobromine auxiliary was modeled after a known P450 3A4 substrate, lisofylline, which is hydroxylated in part at the fourth carbon from the theobromine moiety (Fig. 6) ${ }^{58}$ With a series of small alkanes and alkenes covalently attached to theobromine it was shown that theobromine successfully directs hydroxylation by P450 3A4 at the fourth atom away from the auxiliary for all the compounds that had a fourth methylene carbon (Fig. 7). Double bonds at the third and fourth, or fourth and fifth atoms from the auxiliary led to epoxide formation. Moreover, there was a preference for pro- $R$ facial selectivity at the fourth carbon for both hydroxylation and epoxidation. The presence of double bonds and tertiary $\mathrm{C}-\mathrm{H}$ bonds elsewhere in the molecule did not affect the regioselectivity, in spite of their higher susceptibility towards oxidation. Additionally, no over-oxidation to the ketone and no oxidation of the auxiliary were observed. With its heterocycle, compound $\mathbf{8}$ had two different carbons positioned four atoms away from the auxiliary, and as expected the fourth position closest to the heteroatom was preferred due to electronics. This was the first example of a chemical auxiliary that can predictably direct the site of oxidation based on the distance from the auxiliary.

The authors investigated another potential role for the theobromine auxiliary: facilitating product recovery from whole-cell reaction mixtures. ${ }^{59}$ Product isolation from fermentation reactions is an expensive and time-consuming process that generates large amounts of organic solvent waste. Molecularly imprinted polymers (MIPs) are polymers assembled in the presence of a template. ${ }^{60-68}$ 


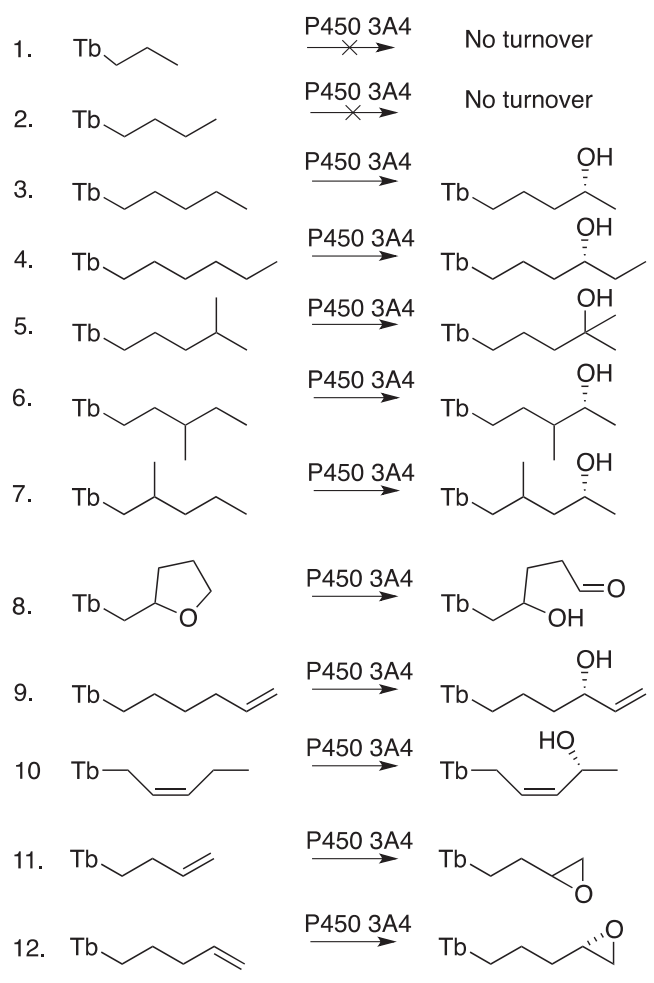

Figure 7. The scope of functionalized theobromine substrates and their conversion products by $\mathrm{P} 4503 \mathrm{~A} 4$; $\mathrm{Tb}$, theobromine. ${ }^{56}$

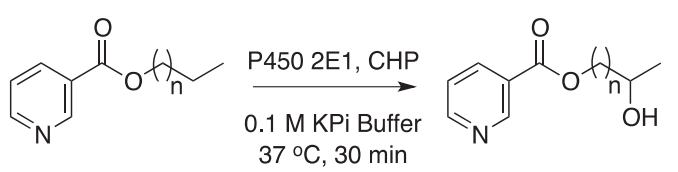

Figure 8. Oxidation of nicotinate containing unnatural substrates by P450 $2 \mathrm{E} 1$. $^{57}$

After removal of the template, MIPs tend to show selective affinity for molecules containing the template moiety. This occurs mainly through non-covalent interactions such as complementarity in size, shape, electrostatics and hydrogen bonding. With the aid of MIPs, the theobromine auxiliary turned out to be an asset to facilitate isolation of the starting materials and products from complex matrices typically used in biotransformations. ${ }^{59}$ Overall, the MIPs captured $>85 \%$ of the theobromine derivatives from complex mixtures and showed high reusability. They also yielded an isolated product of $>90 \%$ purity. These results suggest that chemical auxiliaries can find use not only in controlling the selectivity of P450 transformations but also in facilitating product recovery.

In a subsequent study by the same group, type II P450 ligands proved successful as chemical auxiliaries to direct unnatural substrates to the P450 2E1 active site. ${ }^{57}$ Type II ligands are molecules which coordinate to the heme iron of P450s and are typically viewed as P450 inhibitors. ${ }^{57,69,70}$ Usually, type II ligands have a higher affinity for the active site than similar substrates lacking nitrogen. ${ }^{71-73}$ However, more recent studies have shown that some type II ligands can be metabolized by P450s..$^{71,74-78}$ To design a system with complementary selectivity to that observed with the theobromine auxiliary and P450 3A4, the authors investigated a variety of type II ligands as directing groups for the transformation of various substrates by P450 2E1. ${ }^{57}$ Modeled after methyl nicotinate, a known type II ligand of P450 2E1, ${ }^{72}$ and nicotine-derived nitrosamine ketone, a naturally occurring P450 2E1 substrate, nicotinate proved to be the most useful chemical auxiliary among those tested (Fig. 8). Using a series of nicotinate esters the authors confirmed the preference of P450 2E1 to oxidize aliphatic $\mathrm{CH}_{2}$ or alkenyl $\mathrm{CH}$ groups furthest from the auxiliary $(\omega-1)$, as previously observed for the hydroxylation of fatty acids such as lauric, myristic, palmitic and stearic acids. ${ }^{53,79}$ In the absence of the auxiliary, however, the enzyme did not significantly transform any of the substrates, confirming the role of the auxiliary in forcing biocatalysis in a predictable manner.

\section{Conclusion}

We discussed here two simple and quick strategies reported to increase the substrate scope of P450 biocatalysts without the need for protein mutagenesis. Both decoy molecules and substrate engineering have the ability to influence the substrate specificity as well as the regio- and stereoselectivity of P450-catalyzed reactions. Although these strategies require extra molecules or synthetic steps, this is often offset by a number of advantages, the key one being that the desired products can otherwise require several synthetic steps to be produced. Substrate engineering is largely unexplored in the area of P450 biocatalysis. As well, there is room for further investigation of decoy molecules and other cooperative modulators of P450 activity. The successful stories summarized here justify additional efforts in this area.

\section{Acknowledgments}

Writing of this article and research in the area of P450 enzymes in the Auclair group have been funded by the National Science and Engineering Research Council of Canada (NSERC), the Center in Green Chemistry and Catalysis, Merck Frosst Canada Ltée, Boehringer Ingelheim Canada, and AstraZeneca Canada. V.P. was supported by scholarships from the Dr. Richard H. Tomlinson Foundation, Walter C. Sumner Foundation, and the Centre in Green Chemistry and Catalysis.

\section{References and notes}

1. Bernhardt, R. J. Biotechnol. 2006, 124, 128.

2. Guengerich, F. P. In Cytochrome P450: Structure, Mechanism, and Biochemistry; Ortiz de Montellano, P. R., Ed., 3rd ed.; Kluwer Academic/Plenum: New York, 2005; p 377.

3. Gillam, E. M. J. Clin. Exp. Pharmacol. Physiol. 2005, 32, 147.

4. Guengerich, F. P. Chem. Res. Toxicol. 2001, 14, 611.

5. Urlacher, V. B.; Girhard, M. Trends Biotechnol. 2011, 30, 26.

6. Jung, S. T.; Lauchli, R.; Arnold, F. H. Curr. Opin. Biotechnol. 2011, 22, 809.

7. Munro, A. W.; Girvan, H. M.; Mason, A. E.; Dunford, A. J.; McLean, K. J. Trends Biochem. Sci. 2013, 38, 140.

8. Grogan, G. Curr. Opin. Chem. Biol. 2011, 15, 241.

9. Kumar, S. Expert Opin. Drug Metab. Toxicol. 2011, 6, 115.

10. Meinhold, P.; Peters, M. W.; Hartwick, A.; Hernandez, A. R.; Arnold, F. H. Adv. Synth. Catal. 2006, 348, 763.

11. Fasan, R.; Chen, M. M.; Crook, N. C.; Arnold, F. H. Angew. Chem., Int. Ed. 2007, 46, 8414.

12. Li, Q. S.; Schwaneberg, U.; Fischer, P.; Schmid, R. D. Chem. Eur. J. 2000, 6, 1531.

13. Seifert, A.; Vomund, S.; Frohmann, K.; Kriening, S.; Urlacher, V. B.; Laschat, S.; Pleiss, J. ChemBioChem 2009, 10, 853.

14. Lewis, J. C.; Mantovani, S. M.; Fu, Y.; Snow, C. D.; Komor, R. S.; Wong, C. H.; Arnold, F. H. ChemBioChem 2010, 11, 2502.

15. Kolev, J. N.; Zaengle, J. M.; Ravikumar, R.; Fasan, R. ChemBioChem 2014, 15 , 1001.

16. Fasan, R.; Meharenna, Y. T.; Snow, C. D.; Poulos, T. L.; Arnold, F. H. J. Mol. Biol. 2008, 383, 1069.

17. Zhang, K.; El Damaty, S.; Fasan, R. J. Am. Chem. Soc. 2011, 133, 3242.

18. Zhang, K.; Shafer, B. M.; Demars, M. D.; Stern, H. A.; Fasan, R. J. Am. Chem. Soc. 2012, 134, 18695 .

19. Kolev, J. N.; O’Dwyer, K. M.; Jordan, C. T.; Fasan, R. ACS Chem. Biol. 2014, 9, 164. 20. Guengerich, F. P. Chem. Res. Toxicol. 2008, 21, 70.

21. Guengerich, F. P. Annu. Rev. Pharmacol. Toxicol. 1999, 39, 1.

22. Shoji, O.; Fujishiro, T.; Nakajima, H.; Kim, M.; Nagano, S.; Shiro, Y.; Watanabe, Y. Angew. Chem., Int. Ed. 2007, 46, 3656.

23. Lee, D. S.; Yamada, A.; Sugimoto, H.; Matsunaga, I.; Ogura, H.; Ichihara, K.; Adachi, S.-I.; Park, S.-Y.; Shiro, Y. J. Biol. Chem. 2003, 278, 9761.

24. Fujishiro, T.: Shoji, O.; Watanabe, Y. Tetrahedron Lett. 2011, 52, 395. 
25. Shoji, O.; Fujishiro, T.; Nagano, S.; Tanaka, S.; Hirose, T.; Shiro, Y.; Watanabe, Y. J. Biol. Inorg. Chem. 2010, 15, 1331.

26. Baker, M. T.; Bates, J. N.; Leff, S. V. Anesth. Analg. 1987, 66, 1141.

27. Baker, M. T.; Ronnenberg, W. C., Jr. Toxicol. Appl. Pharmacol. 1992, 114, 25.

28. Want, Y.; Baker, M. T. Drug Metab. Dispos. 1993, 21, 299.

29. Wang, Y.; Olson, M. J.; Baker, M. T. Biochem. Pharmacol. 1993, 46, 87.

30. Zilly, F. E.; Acevedo, J. P.; Augustyniak, W.; Deege, A.; Häusig, U. W.; Reetz, M. T. Angew. Chem. 2011, 123, 2772.

31. Kawakami, N.; Shoji, O.; Watanabe, Y. Angew. Chem., Int. Ed. 2011, 50, 5315.

32. Ueng, Y. F.; Kuwabara, T.; Chun, Y. J.; Guengerich, F. P. Biochemistry 1997, 36, 370.

33. Atkins, W. M. Annu. Rev. Pharmacol. Toxicol. 2005, 45, 291.

34. Leroux, F. ChemBioChem 2004, 5, 644 .

35. Zilly, F. E.; Acevedo, J. P.; Augustyniak, W.; Deege, A.; Häusig, U. W.; Reetz, M. T. Angew. Chem., Int. Ed. 2011, 52, 13483.

36. Shoji, O.; Kunimatsu, T.; Kawakami, N.; Watanabe, Y. Angew. Chem., Int. Ed. 2013, 52, 1.

37. Pietz, S.; Wolker, D.; Haufe, G. Tetrahedron 1997, 4020, 17067.

38. Dawson, M. J.; Lawrence, G. C.; Mayall, J.; Noble, D.; Roberts, S. M.; Turner, M. K.; Wall, W. F. Tetrahedron Lett. 1986, 27, 1089.

39. Holland, H. L.; Brown, F. M.; Larsen, B. G.; Zabic, M. Tetrahedron: Asymmetry $1995,6,1569$.

40. Sundby, E.: Azerad, R.; Anthonsen, T. Biotechnol. Lett. 1998, 20, 337.

41. Virne, B.; Archelas, A.; Fustoss, R. Tetrahedron 1991, 47, 1447.

42. Holland, H. L.; Morris, T. A.; Nava, P. J.; Zabic, M. Tetrahedron 1999, 55, 7441.

43. Braunegg, G.; de Raadt, A.; Feichtenhofer, S.; Griengl, H.; Kopper, I.; Lehmann, A.; Weber, H. Angew. Chem., Int. Ed. 1999, 38, 2763.

44. De Raadt, A.; Griengl, H.; Weber, H. Chemistry 2001, 7, 27.

45. Li, S.; Chaulagain, M. R.; Knauff, A. R.; Podust, L. M.; Montgomery, J.; Sherman, D. H. Proc. Natl. Acad. Sci. U.S.A. 2009, 106, 18463.

46. Münzer, D. F.; Meinhold, P.; Peters, M. W.; Feichtenhofer, S.; Griengl, H.; Arnold, F. H.; Glieder, A.; De Raadt, A. Chem. Commun. 2005, 2597.

47. Lewis, J. C.; Bastian, S.; Bennett, C. S.; Fu, Y.; Mitsuda, Y.; Chen, M. M.; Greenberg, W. A.; Wong, C.; Arnold, F. H. Proc. Natl. Acad. Sci. U.S.A. 2009, 106, 16550.

48. Xue, Y.; Zhao, L.; Liu, H. W.; Sherman, D. H. Proc. Natl. Acad. Sci. U.S.A. 1998, 95, 12111.

49. Xue, Y.; Wilson, D.; Zhao, L.; Sherman, D. H. Chem. Biol. 1998, 5, 661.

50. Li, S.; Podust, L. M.; Sherman, D. H. J. Am. Chem. Soc. 2007, 129, 12940.

51. Negretti, S.; Narayan, A. R. H.; Chiou, K. C.; Kells, P. M.; Stachowski, J. L. Hansen, D. A.; Podust, L. M.; Montgomery, J.; Sherman, D. H. J. Am. Chem. Soc. 2014, 136, 4901.
52. Julsing, M. K.; Cornelissen, S.; Bühler, B.; Schmid, A. Curr. Opin. Chem. Biol. 2008, $12,177$.

53. Chefson, A.; Zhao, J.; Auclair, K. ChemBioChem 2006, 7, 916.

54. Podust, L. M.; Sherman, D. H. Nat. Prod. Rep. 2012, 29, 125.

55. Redlich, G. Zanger, U. M. Riedmaier, S. Bache, N. Giessing A. B. M. Eisenacher, M.; Stephan, C.; Meyer, H. E.; Jensen, O. N.; Marcus, K. J. Proteome Res. 2008, 7, 4678.

56. Larsen, A. T.; May, E. M.; Auclair, K. J. Am. Chem. Soc. 2011, 133, 7853.

57. Menard, A.; Fabra, C.; Huang, Y.; Auclair, K. ChemBioChem 2012, 13, 2527.

58. Shin, H. S.; Slattery, J. T. J. Pharm. Sci. 1998, 87, 390.

59. Larsen, A. T.; Lai, T.; Polic, V.; Auclair, K. Green Chem. 2012, 14, 2206.

60. Cormack, P. A. G.; Elorza, A. Z. J. Chromatogr., B 2004, 804, 173.

61. He, C.; Long, Y.; Pan, J.; Li, K.; Liu, F. J. Biochem. Biophys. Methods 2007, 70, 133.

62. Kist, T. B. L.; Mandaji, M. Electrophoresis 2004, 25, 3492

63. Qiao, F.; Sun, H.; Yan, H.; Row, K. H. Chromatographia 2006, 64, 625.

64. Turiel, E. Martín-Esteban, A Anal. Chim. Acta 2010, 668, 87.

65. Jin, Y.; Row, K. H. Polymer 2007, 28, 276.

66. Theodoridis, G.; Manesiotis, P. J. Chromatogr., A 2002, 948, 163.

67. Tse Sum Bui, B.; Haupt, K. Anal. Bioanal. Chem. 2010, 398, 2481.

68. Cirillo, G.; Curcio, M.; Parisi, O. I.; Puoci, F.; Iemma, F.; Spizzirri, U. G.; Restuccia, D.; Picci, N. Food Chem. 2011, 125, 1058.

69. Vasaitis, T. S.; Bruno, R. D.; Njar, V. C. O. J. Steroid Biochem. Mol. Biol. 2011, 125 23.

70. Mercer, E. I. Lipids 1991, 26, 584

71. Peng, C. C.; Pearson, J. T.; Rock, D. A.; Joswig-Jones, C. A.; Jones, J. P. Arch Biochem. Biophys. 2010, 497, 68.

72. Jones, J. P.; Joswig-Jones, C. A.; Hebner, M.; Chu, Y.; Koop, D. R. Chem. Biol. Interact. 2011, 193, 50.

73. Peng, C. C.; Cape, J. L.; Rushmore, T.; Crouch, G. J.; Jones, J. P. J. Med. Chem. 2008 51,8000 .

74. Pearson, J. T.; Hill, J. J.; Swank, J.; Isoherranen, N.; Kunze, K. L.; Atkins, W. M. Biochemistry 2006, 45, 6341.

75. Dahal, U. P.; Joswig-Jones, C. A.; Jones, J. P. J. Med. Chem. 2012, 55, 280.

76. Pearson, J.; Dahal, U. P.; Rock, D. A.; Peng, C.-C.; Schenk, J. O.; Joswig-Jones, C. A.; Jones, J. P. Arch. Biochem. Biophys. 2011, 511, 69.

77. Chiba, M. Drug Metab. Dispos. 2001, 29, 1.

78. Hutzler, J. M.; Melton, R. J.; Rumsey, J. M.; Schnute, M. E.; Locuson, C. W.; Wienkers, L. C. Chem. Res. Toxicol. 2006, 19, 1650.

79. Adas, F.; Salaün, J. P.; Berthou, F.; Picart, D.; Simon, B.; Amet, Y. J. Lipid Res $1999,40,1990$. 